\title{
Does the severity of pain correlate with severity of functional disability? Factors influencing 'patient reported outcome measures' in spinal patients
}

\author{
Andrew P. MacCormick ${ }^{1, *}$ and Himanshu Sharma ${ }^{2}$ \\ ${ }^{1}$ Plymouth University Peninsula School of Medicine Dentistry, Plymouth, UK \\ ${ }^{2}$ Department of Surgery, Plymouth Hospitals NHS Trust, Derriford Hospital, Plymouth PL6 8DH, UK
}

Received 24 November 2017, Accepted 15 May 2018, Published online 1 October 2018

\begin{abstract}
Aims: To assess correlation between the Visual Analogue Scale (VAS) pain score and the Oswestry Disability Index (ODI) and which patient factors can influence patient-reported outcome measures (PROMs). This study also aims to assess the response to the sexual function question of the ODI.

Methods: Retrospective analysis of 200 consecutive patients undergoing a range of different lumbar spinal procedures between July 2012 and September 2015 was performed. Subgroup analysis was also performed on the 122 patients who underwent microdiscectomy and/or decompression procedures only. Data from notes and clinical letters from the patient's first clinic appointment were collected. In addition to these outcome measures, data were also extracted regarding patients' gender, age, smoking status, alcohol use, employment and mental health status.

Results: Significant correlation was found between VAS pain score and ODI ( $p=0.002)$ and between VAS pain score and question 1 of ODI $(p=0.0001)$. A lower ODI score was reported at time of surgery by those in employment compared to those who are unemployed $(p=0.008)$. In addition to this, a lower ODI score was reported in those who are self-employed compared to those in employment $(p=0.048)$ in both cohorts. A significantly higher mean ODI score was shown within the subgroup analysis for current smokers $(p=0.02)$. None of the other patient factors that were analysed were found to affect PROMs. $65 \%$ of patients answered the sexual function question of the ODI.

Conclusions: Significant correlation was demonstrated between VAS pain score and ODI. Those who are in employment are far more likely to report a lower ODI score than those who are unemployed at the time of surgery. Self-employed patients were found to have reported a significantly lower ODI score than those who are in employment. Smoking cessation should be encouraged as those who are current smokers may be more likely to report a higher ODI. As $65 \%$ of patients decided to answer the sexual function question of the ODI, this supports its further use.
\end{abstract}

Key words: Patient reported outcome measures, PROMs, Oswestry disability index, VAS pain score, Lumbar spinal surgery.

\section{Background}

Back pain has been defined as the leading cause of disability in the UK [1], affecting $15 \%$ of adults and the impact that this can have on a patient's quality of life (QOL) can be severe. Physicians are now encouraged to monitor the impact of a patient's condition on their everyday living both before and after surgery [3].

The Visual Analogue Scale (VAS) and the Oswestry Disability Index (ODI) are two commonly used systems to measure patient-reported outcome measures (PROMs) in

\footnotetext{
*Corresponding author: andy_maccormick@hotmail.co.uk
}

spinal patients. The VAS is a unidimensional measure of pain intensity that is widely used for a range of conditions. The ODI, on the other hand, is a condition-specific measure for the assessment of outcomes in spinal pathologies. This tool, developed by Fairbank [4] in 1980, has been extensively tested by various authors for its applicability and reliability [5]. They concluded that it is an effective instrument for the disability assessment of lumbar spine pathology as it addresses both pain and function (Figure 1).

A range of different patient factors have been shown to also impact these outcome measures. A large proportion of patients who are off work due to their back pain have been 


\section{oswestry low back pain questionnaire}

กdime

date of birth

occupation

how long have you had leg pain?

address how long have you had back pain?

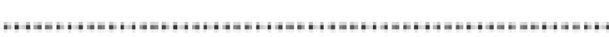

aluse reat:

this quetionn ire has been designed to ghe the doctor intorimation as to how your back pain has affected vour ability to manage in everydyy life - plase answer every sction, B mark in each one

\author{
section 1 - pain intensity \\ $\square$ I can tolsate the pain I hove w thout having to use pain \\ killers \\ g the pain is bad but I munge without baking pain kilers \\ $\checkmark$ pain killess give complete reldef from poin \\ $\square$ pain killers ove moderabe reled from pain

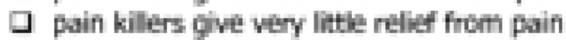 \\ $\square$ pain killers hwe no effect on the puin and I do not use them
}

section 2 - personal care (washing, dressing, tetc)

口 I cai look after inyedf normally w thout causing extra pain

घ I can look after myelf nombly but it causes eatra pain

$\square$ it is pairful to look after myelf and $\mathbb{I}$ am slow and cancul

I nod some help but manage most of my personal care

- II nedd help tevery day in most aspects of seff care

$\square$ Id not qet dressed, wash with difficulty and sty in bed

\section{section $\mathbf{3}$ - lifting}

口 I can lift heary weights without extra pain

$\checkmark$ I can lif heary weights but it gines eatra pain

$\square$ pain provents me from lifting heav weights off the floor, but I can munoge if they are convenienty postioned, eg on a table

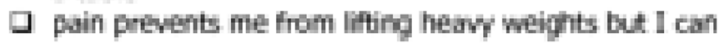
munage light to medum weights if they are convenivatly postioned

- I can lift anly wery light wights

$\square$ I canfot ift or carry anpthing at all

\section{section 4 - walking}

- pain does not prevent the walking any distance

$\square$ paif prevents me walsing more thun 1 mile

[ pain provints me walsing more than $1 / 2$ mile

$\checkmark$ pain prevents me walsing mone than $1 / 4$ mile

- I can orly walk using a stick or crutuhes:

a I am in bed most of the time and have to crast to the toilet

\section{section 5 - sitting}

口 I can st in any chair as long as i like

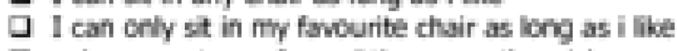

$\square$ pain provthts me from sitting more than 1 hour

] pain prevents me from stting mone than $1 / 2$ hour

a pain provents me from stting mone than 10 minutes

$\checkmark$ pain provents me from sitting al all

\section{comments}

Figure 1. Summary of the ODI.

found to remain off work even after surgery [6], so research is required to assess how the highest level of HRQoL can be achieved. The first step for this process will be to assess date wegks weeks only the one bor which applies to yu. we realise you troy consd. er that 2 satembits in any 1 section relate to you, but please fust

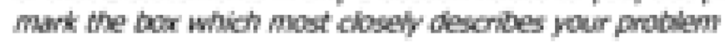

section 6 - standing

马 I cañ sand ad kng as I wart without extra pain

I I can stand as long as I wart but it gives me eatra pain

马 pain prevents me from standing lor more than 1 hour

ป pain prevents me from tarding for more than $1 / 2$ hour

】 pain prevents me from standing for more than 10 minutes.

] pain prevents me from standing at all

\section{section 7 - sleeping}

】 pain dose not prevert me from secping wel

ป I can steep well only by using tablets

I even when I bake tablets I have less than sir hours deep

d even when I tabe tablets II have les than four hours sieep

[ even when I take bablets II have less than two hours deep

J pain prevents me from slexping at all

\section{section 8 - sex life}

】 imp sex la is normal and causes no catra pain

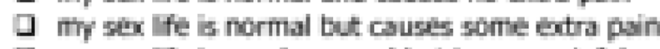

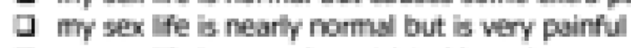

J min ser life is severdy restricted by puin

$\checkmark$ mires le is nearly aboent because of pin

] pain prevents any sex life at all

\section{section 9 - social life}

】 min social life is normul and gives me no extra pain

[ mr social life is nommal but incresses the degree of pain

J pain hise no ignificant effect on my socid life apart from limiting tiy more energetic interest, by danding te

J pain hus resicted social life and I do not go out as often

] pain hus restricted my social lefe to my hothe

] I have no socid life bocause of pain

\section{section 10 - travelling}

I I can travel anyohere without edta pain

] I can travel anywhere but it ghes me extra pain

D pain is bad but I mansge journeys over tho hours

Dain restricts me to journess of bes than one hour

J pain ristricts me to short neobsary journeys of less than $1 / 2$ hour

] pain prevents me from traveling encept to the dactor or hospits

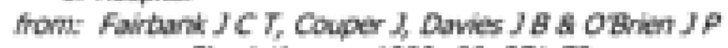
Ansotheripy issot 6t: $27 \cdot 73$

which patient groups to target this at, and hence why this study will aim to assess which patient factors can influence PROMs. 


\section{Aims}

The aims of this study are to assess correlation between the VAS pain score and the ODI and which patient factors can influence PROMs. This study will also assess the response to the sexual function question of the ODI.

\section{Methods}

\section{Patients}

The setting for this study was a multicultural tertiary neurosurgery centre in a developed western country. Retrospective analysis was undertaken on 200 consecutive patients who underwent a range of different lumbar spinal procedures between July 2012 and September 2015. This patient group was defined as cohort 1 . Subgroup analysis for patient factors was also performed on the 122 patients within this cohort who underwent microdiscectomy and/or decompression procedures and this patient group was defined as cohort 2. Inclusion criteria were that the patients were all seen within this time period and were all under the care of and operated on by the same surgeon to ensure consistency of data. All patients with incomplete information regarding their VAS pain score or ODI score were excluded from this analysis and the subsequent data interpretation. When statistical analysis was required, patients were divided into VAS groups based on their level of pain: mild $(<4)$, moderate $(5-7)$ and severe $(>8)$.

\section{Treatment}

All of the patients in the main cohort group underwent a range of different lumbar spinal procedures including microdiscectomy, decompression, fusion, nerve root injection and laminectomy. The patients in the subgroup only underwent microdiscectomy and decompression procedures. These operations were performed by the same surgeon who saw them at their first clinic consultation.

\section{Outcome measure and baseline data}

Data were collected using the notes and clinical letters from the patient's first clinic appointment. PROMs were all taken at this appointment including ODI and VAS pain score. The ODI index, which includes 10 items, is a commonly used outcome measure for reporting how a patient's back or leg pain is affecting their ability to manage daily living. Recent literature has demonstrated that it shows good psychometric properties and is an effective tool for reporting functional outcome following spinal surgery [7]. Each of the 10 items on the index is scored from 0 to 5 , with the maximum possible score being 50 [8]. To achieve a percentage, as is reported in this study, the total score must be multiplied by 2 . Patients were not grouped on the basis of their ODI score. The VAS pain scale is one of the most commonly used methods to record patient pain [10]. Patients were asked to report their
Table 1. Divisions within each patient factor group.

\begin{tabular}{|c|c|c|c|c|}
\hline Patient Factor & \multicolumn{4}{|c|}{ Groups Divisions } \\
\hline Age & $<40$ & \multicolumn{2}{|l|}{$40-60$} & $>60$ \\
\hline Smoking Status & Current Smoker & \multicolumn{2}{|l|}{ Ex-Smoker } & Never Smoked \\
\hline Alcohol Use & $\begin{array}{l}\text { Heavy (>14 units } \\
\text { per week) }\end{array}$ & \multicolumn{2}{|c|}{ Mild (<14 units per week } & None \\
\hline Employment & Employed & Self Employed & Retired & Unemployed \\
\hline Mental Health Status & \multicolumn{2}{|c|}{ Known mental health condition } & \multicolumn{2}{|c|}{ No known mental health condition } \\
\hline
\end{tabular}

current level of back and leg pain on a scale of $0-10$, representing a scale of pain from none at all to the most excruciating pain possible.

In addition to these outcome measures, data were also extracted regarding patients' gender, age, smoking status, alcohol use, employment and mental health status. This was also obtained from the notes and clinical letters from patients' first clinic appointment.

\section{Statistical analysis}

Statistical analysis was performed using the SPSS statistical software [10]. VAS pain score and ODI score were analysed using a two-sample (unpaired) $t$-test to analyse the difference between the means. Mean ODI score was compared with mean VAS pain score for each of the mild, moderate and severe groups.

When considering the other patient factors, the same statistical analysis software and method was used. The divisions within each of these groups are demonstrated in Table 1. A $p$ value for all data of $<0.05$ was considered significant.

\section{Results - main cohort \\ Correlation between VAS pain score and ODI}

Results from all 200 patients were obtained. Significant correlation was found in all groups of patients. When comparing the mild VAS pain score group to the moderate group, a difference in mean overall ODI score of 10.2 was found $(p=0.002$ (95\% CI 3.83-16.58)). A similar difference was also seen when comparing the moderate group to the severe group, when an average ODI score difference of 11.19 was found $(p \leq 0.0001$ (95\% CI 6.28 16.10)) (Figure 2).

Statistical significance was also found when comparing VAS pain score to question 1 of the ODI, that being the question focusing on the severity of current pain levels. Comparing the moderate group to the severe group, there was an average question 1 VAS pain score difference of $0.65 \quad(p=0.0001 \quad(95 \%$ CI $0.33-0.96))$ (Figure 3).

\section{Impact of patient factors on outcome measures}

Employment status was found to have the most significant impact on PROMs. A significantly lower 


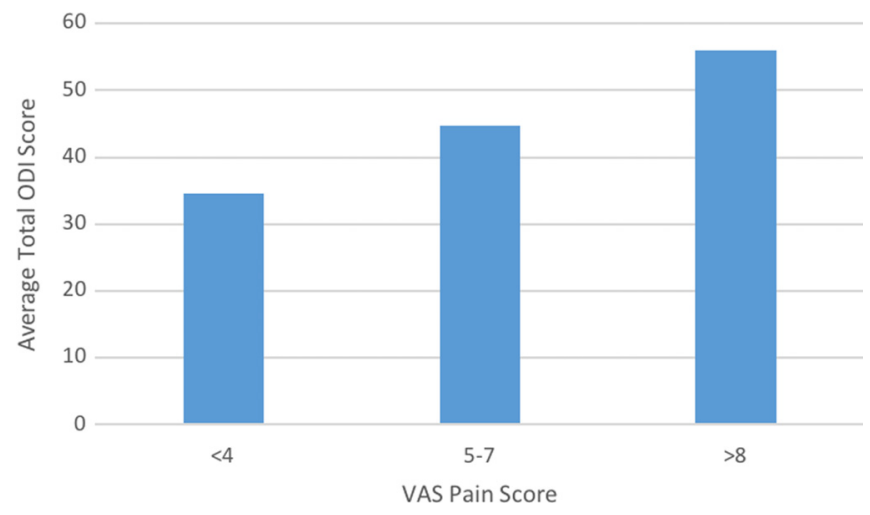

Figure 2. Graph comparing VAS pain score with average total ODI score.

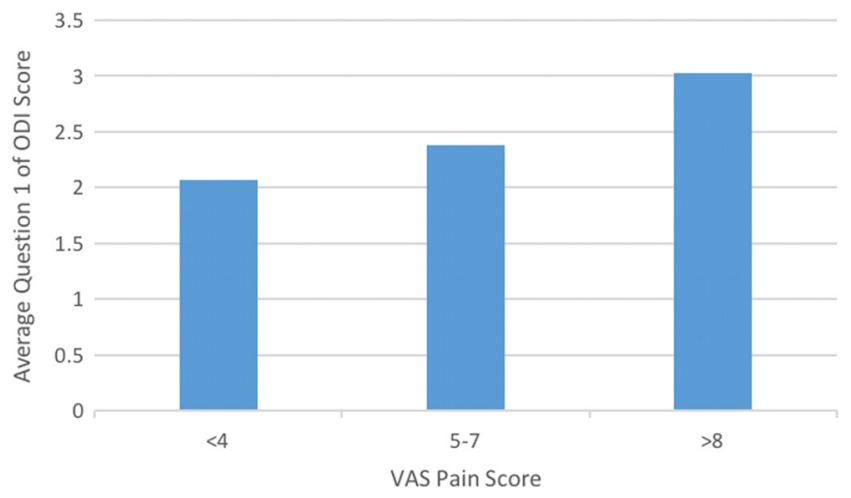

Figure 3. Graph comparing VAS pain score with average question 1 score of the ODI.

mean ODI score was found when comparing those who are self-employed $(n=22)$ to those who are in public or private sector employment $(n=46)$. An ODI difference of $6.8(p=0.0479$ (95\% CI $0.06-13.57))$ was observed (Figure 4).

Furthermore, more significant results were seen when comparing those who are currently in any form of employment $(n=68)$ to those who are unemployed $(n=29)$. An ODI difference of $12.2(p=0.0078(95 \%$ CI 3.24-20.76)) was found, with those who are in employment reporting a lower ODI score (Figure 5).

When considering the other patient factors that were analysed: age, gender, smoking status and alcohol use, no other statistically significant differences were found within these groups. The results that were obtained are shown in Table 2 .

\section{Response to question 8 (sexual function) of the ODI}

Of the 200 patients, 130 patients $(65 \%)$ chose to answer question 8 , regarding sexual function, of the ODI while 70 patients $(35 \%)$ chose not to. In the patients who declined to answer this question, this had no bearing on their responses to the rest of the questions as a completion rate of $100 \%$ was achieved for the questionnaire (Figure 6).

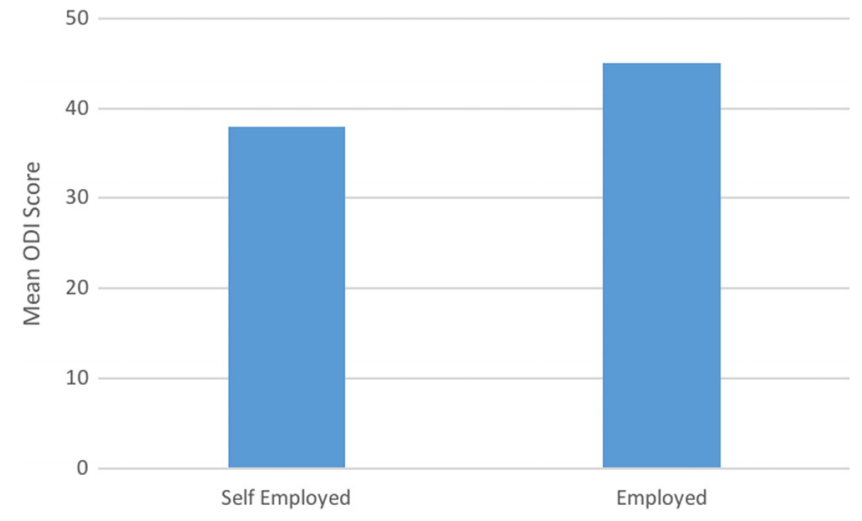

Figure 4. Graphical representation of the mean ODI score of those that are self-employed compared to those in employment.

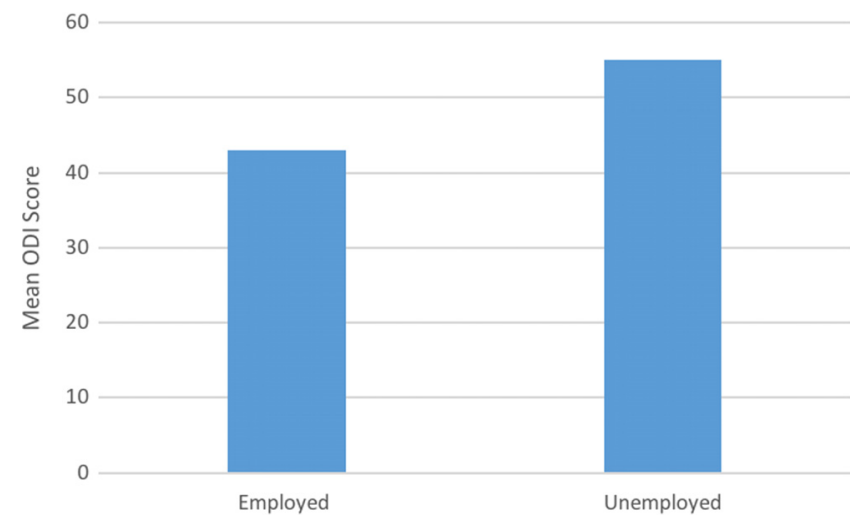

Figure 5. Graphical representation of the mean ODI score of those that are employed compared to those that are unemployed.

Table 2. Summary of the results of the impact of the other measured patient factors on ODI within Cohort 1.

\begin{tabular}{|l|l|l|l|l|}
\hline $\begin{array}{c}\text { Patient Factor } \\
\text { Parameter }\end{array}$ & \multicolumn{3}{|c|}{ Cohorts Analysed } & $\begin{array}{c}\text { Was Statistical } \\
\text { Significance } \\
\text { Established When } \\
\text { Compared to } \\
\text { Total ODI Score? }\end{array}$ \\
\hline Age & $<40(n=52)$ & $40-60(n=61)$ & $>60(n=87)$ & NO $(p=0.311)$ \\
\hline Gender & Male $(n=93)$ & Female $(n=107)$ & NO $(p=0.190)$ \\
\hline Alcohol Usage & $\begin{array}{l}\text { Heavy } \\
(n=29)\end{array}$ & $\begin{array}{l}\text { Mild } \\
(n=134)\end{array}$ & $\begin{array}{l}\text { None } \\
(n=37)\end{array}$ & NO $(p=0.262)$ \\
\hline Smoking Status & $\begin{array}{l}\text { Current Smoker } \\
(n=51)\end{array}$ & $\begin{array}{l}\text { Ex Smoker } \\
(n=24)\end{array}$ & $\begin{array}{l}\text { Never Smoked } \\
(n=125)\end{array}$ & NO $(p=0.350)$ \\
\hline
\end{tabular}

\section{Results - subgroup analysis Impact of patient factors on outcome measures}

The results from the subgroup analysis of cohort 2 also demonstrated a significantly lower mean ODI score in those who are self-employed $(n=15)$ compared to those who are in any public or private sector employment $(n=31)$. There was a mean ODI score difference of 7.2 $(p=0.032(95 \%$ CI $0.91-13.32))$ with those who are selfemployed reporting the lower scores. 


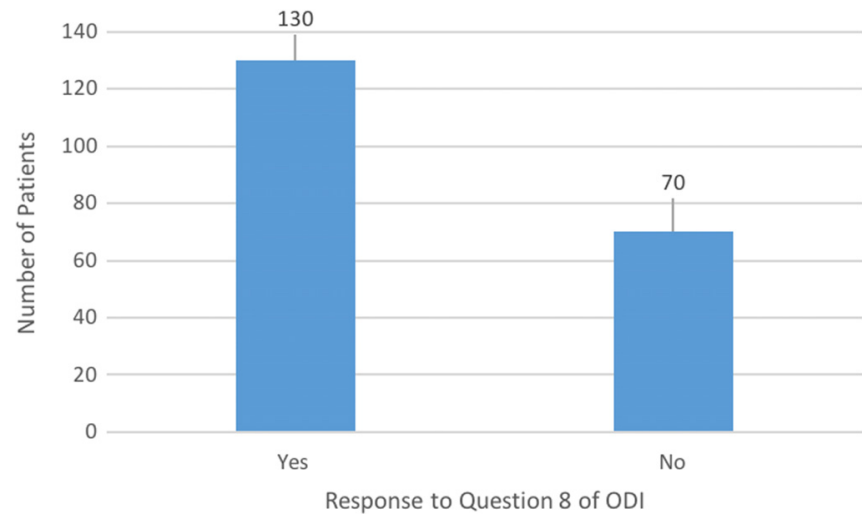

Figure 6. Graphical representation of the response to question 8 of the ODI.

Furthermore, similarly significant results were also found when comparing those who are currently in any form of employment, including self-employed, $(n=46)$ to those who are unemployed $(n=29)$. A mean ODI score difference of $11.2(p=0.0092$ (95\% CI 2.98-18.76)) was demonstrated.

Interestingly, within this subgroup analysis, a significant difference was found when comparing those who currently smoke with those who have never smoked. A mean ODI score difference of $7.9(p=0.02$ (95\% CI 1.12-14.76)) was shown with those who have never smoked demonstrating the lower mean ODI score.

As with cohort 1, no statistically significant differences were found when analyzing age, gender and alcohol use.

\section{Discussion}

The significant correlation between the VAS pain score and the ODI demonstrated in this study supports their simultaneous use to enable both corroboration of score and further understanding of different sources of pain. The main conclusion from a recent meta-analysis found 'little correlation between the VAS pain score and ODI', so extensive further research was recommended in order to assess the correlation between these two measures further [11]. The results from this study aim to do this by clearly demonstrating the positive correlation between these two measures, thus further supporting the need for further research into this topic.

Due to the high percentage of those with back pain not returning to work after surgery, further consideration into the reasons behind this is essential. Recent studies have highlighted the need for research to occur into the impact of employment status on PROMs [13], and this was in keeping with this studies finding of employment status being the only patient factor to do this. Those in employment were shown to be more likely to report a lower ODI score than those who are currently unemployed. While assumptions that those who are unemployed may be somewhat exaggerating, the degree of their disability cannot be made from this study alone, this must be considered. Along with this, findings from this study that those who are self-employed were more likely to report a lower ODI score than those in employment is in line with recent literature. This demonstrated that those who are self-employed are likely to be more determined to return to work quicker than those who are employed by a company due to their lack of entitled sick pay [14]. This is an important consideration when assessing the reasons why some patients fail to return to work after surgery.

The subgroup analysis of the microdiscectomy and decompression patient cohort demonstrated a significantly greater mean ODI score in those that currently smoke. Recent literature has demonstrated increased complication rates in smokers [15], so this adds further evidence to the importance of counselling smokers with regard to cessation prior to their procedure as this could also impact the long-term outcomes after their operation.

Significant attention has also been given to question 8 of the ODI in recent research, providing conflicting information. Response rates of $18 \%$ [16], 36\% [17] and $52 \%$ [18] have been found for this question on three recent large studies. The response rate of $65 \%$ found in this study is higher than the other pieces of literature; this, however, still does show that there is a degree of apprehension from patients regarding the completion of this question.

\section{Limitations}

The greatest limitation within this study is the inclusion of a range of different lumbar spinal procedures in the main cohort of patients which ranged from nerve root blocks to spinal fusions. As a result of this, the subgroup analysis was performed on the biggest patient population that shared the same operative procedure. The patient cohort size for this study was moderate but was strengthened due to the single surgeon experience that was involved in the analysis in order to maintain consistency of data.

\section{Conclusion}

This study has demonstrated significant correlation between the VAS pain score and the ODI. This serves to support their simultaneous use in clinical practice. In addition to this, employment status and smoking status have been shown to have a significant impact on PROMs. This should be taken into consideration in clinical practice as additional measures could be put in place in order to try and encourage eventual return to employment and smoking cessation. A response rate of the sexual function question of the ODI of $65 \%$ is considered adequate and this encourages its continued use.

\section{Conflict of interest}

The authors declare that they have no conflict of interest. 


\section{References}

1. Hoy D, March L, Brooks P, et al. (2014) The global burden of low back pain: estimates from the Global Burden of Disease 2010 study. Ann Rheum Dis 73, 968-974.

2. Kreis S, Molto A, Bailly F, et al. (2015) Relationship between optimism and quality of life in patients with two chronic rheumatic diseases: axial spondyloarthritis and chronic low back pain: a cross sectional study of 288 patients. Health Qual Life Outcomes 13, 78 .

3. Asher AL, Chotai S, Devin CJ, et al. (2016) Inadequacy of 3month Oswestry Disability Index outcome for assessing individual longer-term patient experience after lumbar spine surgery. J Neurosurg Spine 18, 1-11.

4. Fairbank JC, Pynsent PB (2000) The Oswestry Disability Index. Spine 25(22), 2940-2952.

5. Fisher K, Johnson M (1997) Validation of the Oswestry low back pain disability questionnaire, its sensitivity as a measure of change following treatment and its relationship with other aspects of the chronic pain experience. Physiother Theory Pract 13, 67-80.

6. Wynne-Jones G, Cowen J, Jordan J (2014) Absence from work and return to work in people with back pain: a systematic review and meta-analysis. Occup Environ Med $71(6), 448-456$

7. Lee J, Lee M, Kim J, et al. (2015) Pain relief scale is more highly correlated with numerical rating scale than with visual analogue scale in chronic pain patients. Pain Physician 18(2), E195-E200

8. Fairbank J, Couper J, Davies J, et al. (1980) The Oswestry low back pain disability questionnaire. Physiotherapy 66, $271-273$
9. Martins P, Couto T, Gama A (2015) Auditory-perceptual evaluation of the degree of vocal deviation: correlation between the Visual Analogue Scale and Numerical Scale. Codas 27(3), 279-284.

10. Lorenzo-Seva U, Ferrando P (2015) POLYMAT-C: a comprehensive SPSS program for computing the polychoric correlation matrix. Behav Res Methods 47(3), 884-889.

11. DeVine J, Norvell DC, Ecker E, et al. (2011) Evaluating the correlation and responsiveness of patient-reported pain with function and quality-of-life outcomes after spine surgery. Spine 36(21), S69-S74

12. Luckenbill D, Goswam R., Grannis KA, et al. (2015) Retrospective lumbar fusion outcomes measured by ODI sub-functions of 100 consecutive procedures. Arch Orthop Trauma Surg 135(4), 455-464.

13. Irmak R, Baltaci G, Ergun N (2016) Long term test-retest reliability of Oswestry Disability Index in male office workers. Work 53(3), 639-642.

14. Rietveld CA, Hessels J, Van der Zwan P (2015) The stature of the self-employed and its relation with earnings and satisfaction. Econ Hum Biol 17, 59-74.

15. McCunniff PT, Young ES, Ahmadinia K, et al. (2016) Smoking is associated with increased blood loss and transfusion use after lumbar spinal surgery. Clin Orthop Relat Res 474(4), 1019-1025.

16. Goni VG, Hampannavar A, Gopinathan NR, et al. (2014) Comparison of the Oswestry Disability Index and Magnetic Resonance Imaging Findings in Lumbar Canal Stenosis: an observational study. Spine J 8(1), 44-50.

17. Aithala JP (2015) Difficulties in using Oswestry Disability Index in Indian patients and validity and reliability of translator-assisted Oswestry Disability Index. J Orthop Surg Res 10, 90.

18. Costa M, Laurence A, Marshman M (2015) Sex life and the Oswestry Disability Index. Spine J 15(6), 1225-1232.

Cite this article as: MacCormick AP, Sharma H (2018) Does the severity of pain correlate with severity of functional disability?

Factors influencing 'patient reported outcome measures' in spinal patients. SICOT-J, 4, 43. 